\title{
Anatomical Studies on the Sublingual Caruncles of the Goat
}

\author{
Mohamed A. A. Mahdy ${ }^{1, *}$, Kamal E. H. Abdalla ${ }^{2}$, Salma A. Mohamed ${ }^{1}$ \\ ${ }^{1}$ Faculty of Veterinary Medicine, South Valley University, Qena 83523, Egypt \\ ${ }^{2}$ Faculty of Veterinary Medicine, Assiut University, Assiut 71515, Egypt \\ *Corresponding Author: drmohamedhady@yahoo.com
}

Copyright (C) 2013 Horizon Research Publishing All rights reserved.

\begin{abstract}
The present study was carried out to investigate the structure of the sublingual caruncles of the goat. Specimens were studied by gross anatomy, morphometery, light and scanning electron microscopy. Results show that the sublingual floor of the oral cavity consisted of a rostral prefrenular part and two lateral sublingual recesses. The sublingual caruncles had a rostrolaterally directed serrated border, this border divided into three papillae differ in shape and direction. At higher magnification, the surface of sublingual caruncle showed two patterns of microplicae. This study provides a baseline data for clinical studies, this is the first study provide detailed structure of the sublingual caruncle of goat.
\end{abstract}

Keywords Sublingual Caruncle, Goat, SEM (Scanning electron microscopy)

\section{Introduction}

The sublingual floor of the oral cavity is a crescent-shaped space that becomes visible when the tongue is raised [2,9]. It consists of a rostral, prefrenular part and two lateral sublingual recesses $[9,11]$. The sublingual caruncle (Caruncula sublingualis) of the domestic animals is a flattened papilla present on either side of the lingual frenulum $[5,9]$.

Few studies demonstrate the sublingual caruncle in cow and buffalo [1], and in yak [11]. The aim of this study is to provide the structure of the sublingual caruncles in details in order to help the clinical studies, and to compare the morphological differences between animals. To our knowledge, this is the first time to provide a SEM of the sublingual caruncle in the goat.

\section{Materials and Methods}

The present study was carried out on twelve goat heads of both sexes. Samples were obtained from normal adult goats collected from Qena Governorate, Egypt. For SEM specimens washed with acetic acid $2 \%$ and normal saline, then fixed in $4 \%$ glutraldehyde for 24 hours, then post fixed in $2 \%$ buffered osmium tetraoxide. The fixed samples were washed in $0.1 \mathrm{M}$ cacodylate buffer at $\mathrm{PH} 7.3$, and then dehydrated in ascending grades of ethanol, critical point-dried in liquid carbon dioxide, and mounted on metal stubs then coated with gold palladium in sputtering device. Specimens were examined and photographed using JSM-4500 LV scanning electron microscope operated at 20 $\mathrm{KV}$. For LM (light microscopy), samples fixed in NBF and dehydrated in ascending grades of alcohol, cleared in methyl benzoate and embedded in paraffin wax. Sections of $5 \mu \mathrm{m}$ thickness were obtained and stained with Mayer's Hematoxylin and Eosin stain [4]. For morphometric study, the different measurements of the tongue were carried using Digital Vernier Caliper.

\section{Results}

The sublingual floor of the oral cavity was crescentic in shape, it consisted of a rostral prefrenular part and two lateral sublingual recesses. The rostral prefrenular part (Figure 1) lied under the apex of the tongue. It was limited rostrally by the lingual surface of the incisors, laterally by the rostral portion of the lower interdental space and ventrally by the body of the mandible. It was relatively short about $33.45 \pm$ $1.31 \mathrm{~mm}$ long (Table 1). It was broad caudally at the level of the frenulum linguae $(19.06 \pm 1.01 \mathrm{~mm}$ wide $)$ to taper immediately behind the incisors $(22.37 \pm 0.97 \mathrm{~mm}$ wide). Therefore, it was triangular in outline.

Table 1. Morphomerical parameters of the sublingual floor of goat in $\mathrm{mm} \pm$ S.D

\begin{tabular}{|c|c|}
\hline Dimensions (in mm) of the sublingual floor. & Mean $(\mathrm{n}=8)$ \\
\hline -Rostral prefrenular part: & \\
-length & $33.45 \pm 1.31$ \\
-width at frenulum linguae & $19.06 \pm 1.01$ \\
-width behind the incisors & $22.37 \pm 0.97$ \\
- Distance between frenulum and caruncle & $11.68 \pm 2.21$ \\
-Length of sublingual caruncle & $7.40 \pm 1.20$ \\
-Distance between two caruncles & $4.67 \pm 0.40$ \\
\hline
\end{tabular}


The mucous membrane of the rostral prefrenular part was thickened to form a white grayish relatively thick gum. This gum extended on the lingual aspects of the necks of the incisors, it was thicker than the gum which covers the labial aspect of the incisors. Caudally, the prefrenular mucous membrane extended dorsally to continue with that of the ventral aspect of the tongue forming a median lingual frenulum about $13.86 \mathrm{~mm}$ rostral to the second lower premolar tooth. The sublingual caruncles were located in the rostral prefrenular part immediately caudal to the level of the corner incisors, they were approximately $11.68 \pm 2.21 \mathrm{~mm}$ from the lingual frenulum. The distance between the medial sides of both the right and left sublingual caruncles was 4.67 $\pm 0.40 \mathrm{~mm}$. Each measured $7.40 \pm 1.20 \mathrm{~mm}$ long. The sublingual caruncle (Figure 1) was represented by slightly raised flattened area with a rostrolaterally directed serrated border. This border was divided into three papillae, the rostral was the largest papilla, the intermediate and the caudal ones were small.

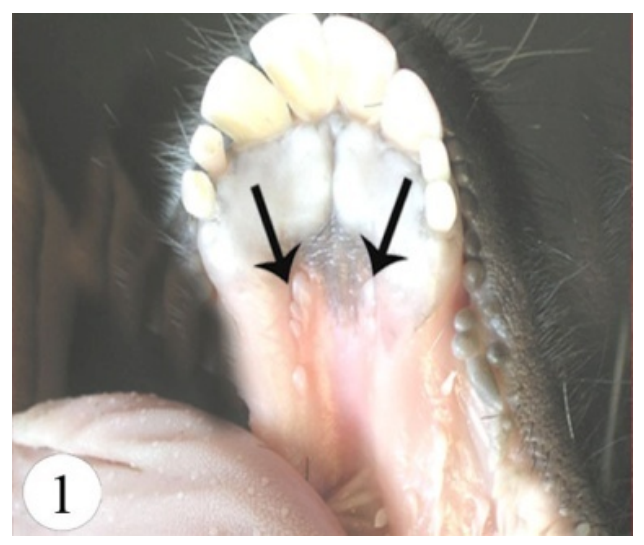

Figure 1. Photograph of the rostral prefrenular part of oral cavity showing the sublingual caruncles (arrows)

The SEM showed that the rostral papilla of the sublingual caruncle had a wide basal part, while its apical part was trifurcated into 3 terminates (Figure 2). The most rostral terminate was directed rostrally, it had a conical shape with pointed summit (Figure 3)

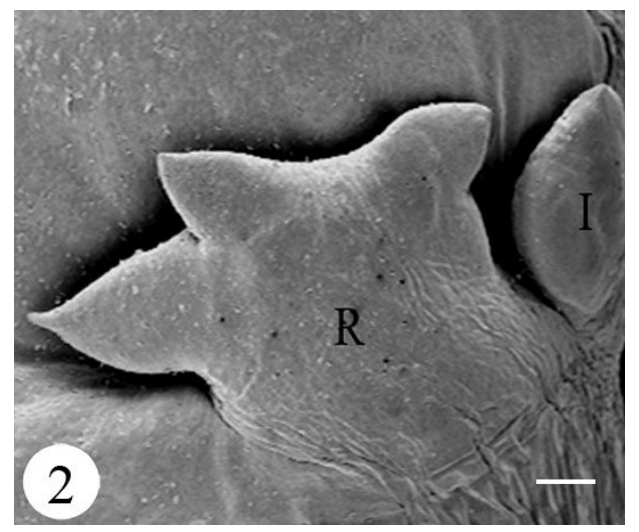

Figure 2. Scanning electron micrograph of the sublingual caruncles showing the rostral papilla (R) trifurcated into three terminates and dome-shaped intermediate papillae (I). Scale bar $=500 \mu \mathrm{m}$

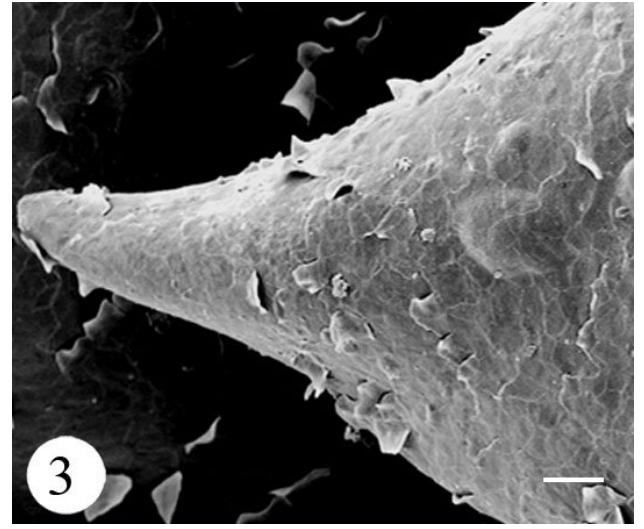

Figure 3. Scanning electron micrograph of the most rostral terminate of the rostral papilla with pointed summit. Scale bar $=40 \mu \mathrm{m}$

The second one was directed rostrolaterally and was smaller than the previous terminate, it had a wart-like shape. The third and the most caudal terminate had the same shape and size as the second one, but it was directed caudolaterally. Therefore the second and third terminates appeared to be diverge from each other. The intermediate papilla of the sublingual caruncle was the smallest one, it was directed laterally and had a dome-like shape. The most caudal papilla was directed rostrolaterally forming finger-like appearance.

At higher magnification, the surface of sublingual caruncle was characterized by presence of winding ridge-like folds; microplicae. Two patterns of microplicae of the epithelial cells could be observed on the sublingual caruncle (Figure 4). In the first pattern, the microplicae run in different directions surrounding numerous micropits of various shapes forming a honeycomb appearance. While in the second pattern, the microplicae were indistinct and the micropits were fewer in number, smaller in size and widely separated from each other in comparison with the first pattern.

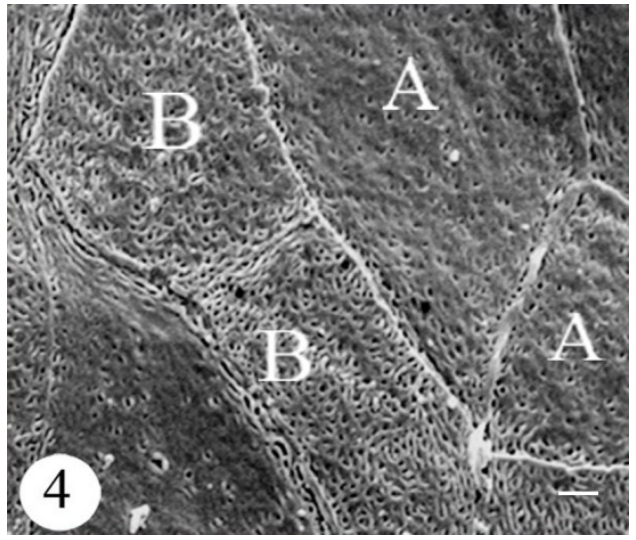

Figure 4. Scanning electron micrograph showing microplicae of the sublingual caruncle. Note two patterns of Microplicae (A, B). Scale bar $=$ $2 \mu \mathrm{m}$

At the level of the LM, the mucous membrane of the sublingual caruncle was lined by highly keratinized stratified squamous epithelium, this epithelium covered dense connective tissue layer of lamina propria (Figure 5). 
Connective tissue papillae of different sizes extended from the lamina propria within the epithelium.

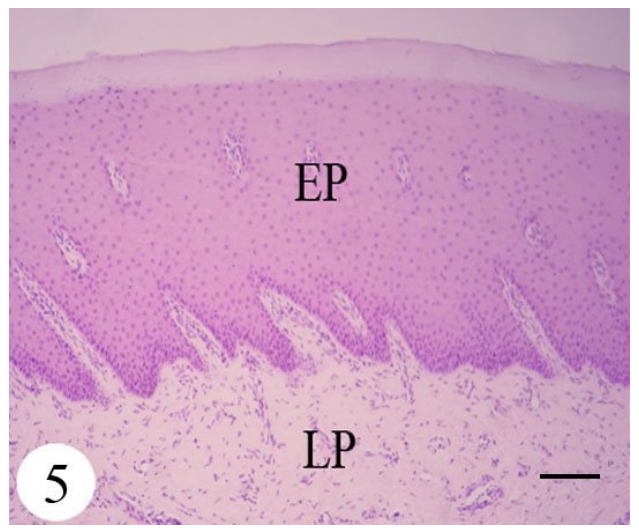

Figure 5. Photomicrograph of the sublingual caruncle showing highly keratinized stratified squamous epithelium (EP) and lamina propria (LP). Stain H\&E, Scale bar $=200 \mu \mathrm{m}$

\section{Discussion}

The present work reveals that the sublingual floor of the oral cavity is a crescentic shaped space. It is relatively short, broad caudally at the level of the frenulum linguae to taper behind the incisors. In camel, the prefrenular part is relatively narrow and short, and extends from the incisors to a level with the first premolar tooth [10]. In contrast to yak, the sublingual floor is broad rostrally to taper behind the incisors [12].

Similarly to the present observation, the sublingual caruncles of the domestic animals are flattened papillae [6, 11].The size and shape of the sublingual caruncles, which serve as the termination sites for the mandibular and major sublingual salivary ducts, vary considerably among species, actual caruncles are absent in pig [14], in deer, they are less distinct than cow and goat [15]. According to the present findings, the sublingual caruncle of the goat has a rostrolaterally directed serrated border, this border is divided into three papillae, the rostral papilla as shown by SEM has a wide basal part, while its apical part is trifurcated into 3 terminates. The intermediate papilla has a dome-like shape, the third and the most caudal papilla forming finger-like appearance. Nearly a similar macroscopical observation was reported in ruminants $[6,9,11]$, cow and buffalo [1] as well as yak [12] in which the sublingual caruncle is a wide, hard papilla with serrated border. In camel, it is represented only by slightly raised area [13], in horse, they are flat and project laterally from the two narrow caruncular folds [11]. In canines, it is a mucosal elevation [7,11]. The sublingual caruncle is a fold of mucosa of the Corpus mandibulae which covers and protects the openings of the mandibular duct [4].

The SEM reveals at higher magnification that the surface of the sublingual caruncle exhibited microplicae. The microplicae show a wide variety of shapes over the surfaces of the cells, they are branching and separated by grooves or holes. In this respect, Grossman [8] stated that, the surfaces of keratinized and non-keratinized oral epithelial cells have a characteristic features which enable these tissue types to be readily distinguished, these features include pits, villus like projection and ridge like folds called microplications. It is suggested that the microplicae may provide protection by reducing the surface area of contact and thereby frictional resistance between opposing surfaces [2]. Another interesting point suggesting that microplicae may be a specific response to environmental abrasive abuse [2]. Grossmann [8] mentioned that the oral surface of the attached gingiva epithelial cell was covered by numerous pits enclosed by a reticular network of interconnecting ridges forming a honeycomb appearance.

\section{Conclusion}

This study provides for the first time detailed SEM of the sublingual caruncle of the goat, this will help to compare the morphological differences with other animal species, moreover help clinical studies for this important part of the oral cavity of the goat.

\section{REFERENCES}

[1] I. H. Ahmed. Surgical affections of the salivary glands in some domestic animals. Ph. D. Thesis, Faculty of Veterinary Medicine, Assiut University, 1988.

[2] P. M. Andrews. Microplicae: characteristic ridge-like folds of the plasmalemma. The Journal of Cell Biology, Vol. 68: 420-429, 1976

[3] J. F. Bone. Animal Anatomy and Physiology. 2nd Ed., Reston Publishing Company Inc. A prentice-Hall Company. Reston, Virginia,1982.

[4] G. M. Constantinescu. Clinical Dissection Guide for Large Animals; Horse, Ox, Sheep, Goat, Pig. Mosby Year Book, Inc, 1991.

[5] R. A. B. Drury, E. A. Wallington. Carleton's Histological Technique. 5th Ed., Oxford University Press, 1980.

[6] M. A. A. El-hagri. Splanchnology of domestic animals. 1st Ed. Cairo Univ. Press, 1967.

[7] C. R. Ellenport. Carnivore digestive system. In: Sisson and Grossman. The anatomy of the domestic animals. Rev. R. Getty. 5 Ed. W. B. Saunders Company. Philadelphia, London, Toronto, 1975 .

[8] E. S. Grossman. A histometric/scanning electron microscope study of normal and loaded oral epithelium of the vervet monkey. J. Anat., 154: 81-90, 1987.

[9] R. E. Habel. Ruminant digestive system. In: Sisson and Grossman. The anatomy of the domestic animals. Rev. R. Getty. 5 Ed. W. B. Saunders Company, Philadelphia, London, Toronto, 1975. 
[10] I. A. Ibrahim. Some anatomical studies on the systema digestorium of camelus dromedaries. M. V. Sc. Thesis, Faculty of Vet. Med., Assiut University,1983.

[11] R. Nickel, A. Schummer, E. Seiferle. The viscera of the domestic mammals. Verlag Paul Parey. Berlin, Hamburg, 1973.

[12] M. Sarma, M. Bhattacharya, K. Sarma, S. N. Katalia. Macro-anatomical study on the sublingual floor of the oral cavity of yak (Bos grunniens). Indian J. Anim. Sci., 65(8):885-886, 1995.
[13] M. M. S Smuts, A. J. Bezuidenhout. Anatomy of the dromedary. Clarendon Press, Oxford, 1987.

[14] J. E. Smallwood. A guide tour of veterinary anatomy. Domestic Ungulates and Laboratory Mammals. W. B. Saunders Company Harcourt Brace Jovanovich, Inc. Philadelphia, London, Toronto, 1992.

[15] A. R. Sreeranjini, C. V. Rajani, N. Ashok. Gross anatomical studies on the hard palate, tonGue and buccal floor in sambar deer (Cervus unicolor). Tamilnadu J. Veterinary and Animal Sciences 6 (4) 151-156, 2010. 